\title{
PROSES PRODUKSI BODY UPPER GENERATING DRUM TYPE CAP.120 T/H
}

\author{
Anggra Fiveriati ${ }^{1}$, Tri Hartutuk Ningsih ${ }^{2}$, Abdul Ghoni $^{3}$ \\ ${ }^{1}$ Politeknik Negeri Banyuwangi \\ 1anggrafiveriati@poliwanggi.ac .id \\ 2,3 Jurusan Teknik Mesin/S1 Teknik Mesin Universitas Negeri Surabaya \\ 2triningsih@unesa.ac.id \\ 3abdulghoni@mhs.unesa.ac.id
}

\begin{abstract}
Abstrak- Jurnal ini menjelaskan proses produksi body upper generating drum type CAP.120 T/H merek AKYAPAK dengan spesifikasi type AHS 30/80 serial SY610-019 produksi 2016 dengan massa $49000 \mathrm{~kg}$ dengan pxlxt 3000x6800x3470. Komponen upper generating drum adalah salah satu komponen pada boiler pipa air yang berfungsi sebagai reservoir campuran air dan uap air, dan juga berfungsi untuk memisahkan uap air dengan air pada proses pembentukan uap superheater. Namun tidak semua boiler pipa air (water tube) yang menggunakan upper generating drum ini. Boiler supercritical beroperasi pada tekanan sangat tinggi di atas tekanan kritis, sehingga tidak dimungkinkan terbentuk gelembung-gelembung uap air, karena itulah boiler supercritical tidak memerlukan upper generating drum untuk memisahkan air dengan uap air. Air feed water yang disupply oleh boiler feed water pump, masuk ke boiler menuju economiser dan selanjutnya masuk ke upper generating drum. Dari upper generating drum, air dipompa oleh pompa sirkulasi boiler menuju ke raiser tube/wall tube untuk dapat mencapai fase uap saturasi. Dari raiser tube air kembali masuk ke upper generating drum. Proses Proses produksi body upper generating drum di PT. Bromo Steel (PT. BOSTO) Indonesia melewati beberapa tahapan yaitu : persiapan material, persiapan marking cutting, proses marking cutting, proses rolling, proses welding, dan terakhir yaitu proses control product (QC) untuk menjamin kualitas pengerjaan.
\end{abstract}

Kata Kunci-Body Upper Generating Drum, Boiler Pipa Air, Boiler Supercritical, Air Feed Water, Economiser.

Abstract - This journal explained the production process body upper generating drum type CAP.120 T/H with brand AKYAPAK spesifikation AHS 30/80 type SY610-019 production year 2016 with massa $49000 \mathrm{~kg}$ dimention pxlxt 3000x6800x3470. A component of the upper generating drum is one of the components to the boiler water pipes that serves as a reservoir a mixture of water and water vapor, and also serves to separate water vapor with water to the process the formation of vapor superheater. But not all the boiler water pipes (water tube) who uses the upper generating. This drum supercritical boilers operates at very high pressures on the critical pressure, so that no possible formed bubbles water vapor, that is why the boiler supercritical does not require the upper generating drum to separate the water with water vapor. Water feeds water which disupply by boiler feed water pump, get into the boiler to economiser and then get into the upper generating. Drum of upper generating, drum water pumped by pumps circulation boiler headed to raisers tube/wall the tube to reach saturation. Steam phase from raisers tube water back into the upper generating. Drum the process of the production process body upper generating a drum in PT. Bromo Steel (PT. BOSTO) Indonesia through several stages of preparation that is: material cutting, marking preparation the process of cutting, marking the process of rolling, the process of welding, and last of the process of control product $(Q C)$ to ensure the quality of components upper generating drum.

Key Words_-Body Upper Generating Drum, Water Tube, Boiler Supercritical, Air Feed Water, Economiser.

\section{Pendahuluan}

Upper generating drum adalah salah satu komponen pada boiler pipa air yang berfungsi sebagai reservoir campuran air dan uap air, dan juga berfungsi untuk memisahkan uap air dengan air pada proses pembentukan uap superheater. Namun tidak semua boiler pipa air (water tube) yang menggunakan upper generating drum ini. Boiler supercritical beroperasi pada tekanan sangat tinggi di atas tekanan kritis, sehingga tidak dimungkinkan terbentuk gelembung-gelembung uap air, karena itulah boiler supercritical memerlukan upper generating drum untuk memisahkan air dengan uap air.

\section{A. Pengertian Upper Generating Drum}

Pada komponen upper generating drum, air feed water yang disupply oleh boiler feed water pump, masuk ke boiler menuju economiser dan selanjutnya masuk ke upper generating drum.

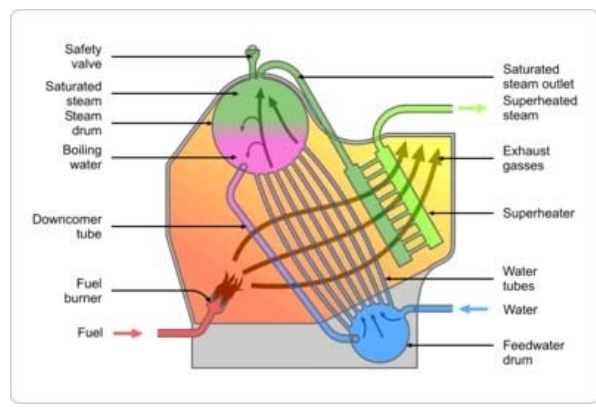

Gbr. 1 Upper Generating Drum

Sumber: Artikel Teknolog 
Pada komponen upper generating drum, air dipompa oleh pompa sirkulasi boiler menuju ke raiser tube/wall tube untuk dapat mencapai fase uap saturasi. Dari raiser tube air kembali masuk ke upper generating drum. Komponen di dalam upper generating drum memungkinkan terjadi pemisahan antara air dengan uap air, sehingga air dipompa kembali menuju raiser tube, sedangkan uap akan menuju ke pipa boiler sisi superheater. Uap saturated yang masuk ke pipa-pipa superheater dipanaskan lebih lanjut sehingga dapat mencapai uap superheater dan memenuhi syarat untuk masuk turbin uap.

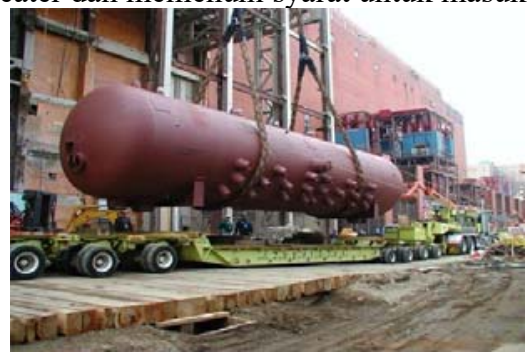

Gbr. 2 Upper Generating Drum

(Sumber: PT. Bromo Steel Indonesia (BOSTO))

\section{B. Planning Control}

Berikut ini merupakan tugas-tugas dari divisi Planning control yaitu:

1. Scheduling

Scheduling adalah tahap pengaturan jadwal kapan proses produksi akan dilangsungkan. Menyusun rencana produksi dengan tujuan dapat berproduksi dengan lancar, tepat waktu dan ekonomis, sehingga mampu memenuhi permintaan pelanggan sesuai dengan yang diharapkan. Rencana produksi sangat menentukan efektifitas fungsi yang berhubungan dalam persiapan, pelaksanaan, dan pengendalian.

Adapun rumus acuan yang digunakan PT. BOSTO dalam membuat schedule proses produksi, yaitu:

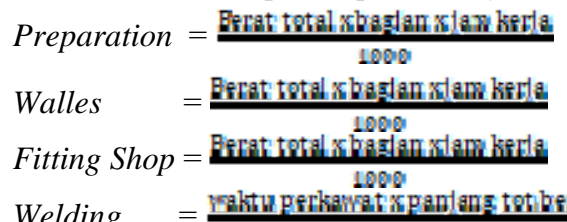

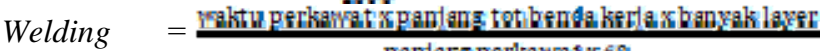

2. Pembuatan Progress Report pantarg perkawa 1 \%8

Divisi Planning Control bertugas mencatat hasil progress dari setiap proses produksi yang dilakukan. Dengan adanya progress report ini dapat memudahkan mengetahui perkembangan setiap pekerjaan yang dilakukan.

a) Metode Proses

Divisi yang bertugas mengatur, merencanakan waktu produksi (Schedule fabrikasi) dan mengawasi jalannya produksi. Adapun tugas-tugasnya adalah sebagai berikut:

1. Memecah gambar

Divisi metode proses bertugas untuk memecah gambar yang utuh atau menggambar ulang gambar yang turun dari departemen engineering. Bertujuan untuk mendetailkan gambar yang sulit dipahami agar memudahkan dibaca saat proses produksi oleh para tenaga kerja di lapangan.

2. Membuat Cutting Plan
Cutting plan adalah proses perencanaan pemotongan material agar memudahkan proses produksi di lapangan. cutting plan berisi potongan-potongan gambar yang terbagi menjadi beberapa segmen yang menunjukkan bentuk potongan dari masing-masing item beserta jenis material, ukuran maupun tebal plat. Sebelum membuat cutting Plan terlebih dahulu menghitung bentangan dari masing-masing bagian.

3. Membuat Job Tiket

Job Tiket atau kartu kerja adalah selembar tiket yang digunakan untuk mengetahui suatu proses pekerjaan yang telah dilakukan meliputi jumlah produk yang dikerjakan, pekerjaan yang harus dilakukan, jam kerja, nama barang, dan tempat pengerjaan.

4. Membuat Bon Material

Bon Material merupakan lembaran surat yang digunakan untuk menuliskan kebutuhan material yang akan digunakan dalam proses produksi. Bon material tersebut akan dikirim ke bagian gudang untuk disiapkan. 1. Departemen Logistik

Departemen logistik bertanggung jawab dalam pengelolaan stock dan distribusi produk. Departemen logistik meliputi:

a. Gudang/operator Warehouse

- Melakukan penyimpanan barang melalui pengolahan dan perintah muatan

- Bertanggung jawab atas pelaksanaan bongkar muat barang di gudang dan mendatangani surat penerimaan barang dan surat jalan

- Bertanggung jawab atas kebersihan dan kerapian gudang

- Melaporkan stok barang dan melakukan stock opname

b. Driver

Driver atau sopir bertugas dalam membawa barang yang akan dikerjakan menuju pabrik dan mengirimkan barang yang sudah dikerjakan kepada customer.

2. Departemen Maintenance

a. Electrician bertugas melaksanakan perawatan dan perbaikan sistem instalasi elektrik atas semua fasilitas mesin produksi baik bersifat rutin maupun non rutin untuk menjamin kelancaran aktifitas produksi.

b. Machine bertugas melakukan pemeriksaan hariansemua mesin produksi dan utility sesuai point check pada form daily checksheet, melakukan corrective action terhadap mesin produksi dan utility yang mengalami gangguan dengan cepat dan tepat sesuai prosedur corrective maintenance.

3. Departemen Plate Work

a. Preparation, melakukan proses marking dan cutting sebelum dilakukan proses assembling sesuai dengan Cutting Plan.

b. Assembling, melakukan proses bevel dan fitup pada plat yang sudah di roll. 
c. Welding, melakukan pengelasan logam/plat

d. Grinding/Finishing, melakukan pembersihan terhadap terak-terak yang terdapat pada benda kerja.

4. Departemen Machining

Machining bertugas mengoperasikan mesin produksi, kendaraan ataupun alat manual.

a. Departemen Pengadaan

Memiliki wewenang untuk mencari pemasok, menerima purchase requisition, melaksakan pembelian bahan baku.

b. Departemen SDM dan Keamanan

c. HRD/legal bertugas dalam penerimaan, penempatan, dan pembinaan karyawan.

d. Satpam bertugas menjaga keamanan secara menyeluruh di lingkungan perusahaan, memeriksa setiap tamu yang memasuki area perusahaan, menertibkan parkir motor dan mobil.

\section{METODE}

Proses produksi body upper generating drum ini secara garis besar dibagi menjadi 3 tahap, yaitu: marking cuting, rolling dan welding.

\section{a. Marking Cuting}

Setelah gambar diolah oleh departemen PPC, gambar akan langsung diturunkan ke departemen produksi bagian preparation (marking cuting). Dimana jobdisk dari tim preparation adalah mengolah barang mentah berupa plat baja untuk ditandai dan kemudian dipotong sesuai gambar pesanan.

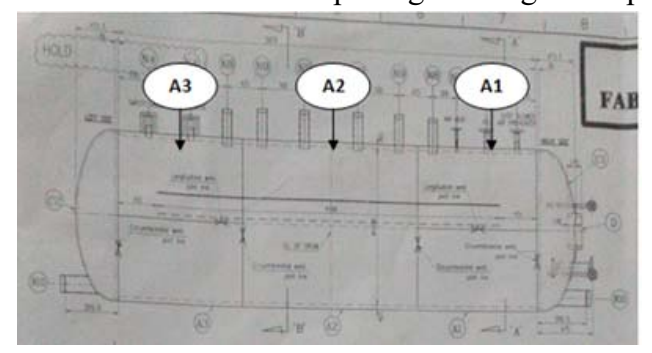

Gbr. 3 Pesanan Upper Generating Drum

(Sumber: PT. Bromo Steel Indonesia (BOSTO))

Pesanan yang harus dikerjakan sesuai gambar adalah gambar A1, A2, dan A3. Gambar A1 dan A3 mempunyai ukuran yang sama yaitu roll plate dengan ukuran diameter $1600 \mathrm{~mm}$ dengan panjang $1474 \mathrm{~mm}$ dan tebal $46 \mathrm{~mm}$. Gambar A2 mempunyai ukuran yang lebih panjang yaitu $2118 \mathrm{~mm}$ dengan diameter dan tebal yang sama. Untuk proses marking cuting harus diketahui dahulu ukuran bentangan dari plat, yaitu menggunakan rumus dibawah ini.

$$
\begin{aligned}
\text { Bentangan } & =(\text { ID }+ \text { tebal plat }) \times \pi \\
\text { Bentangan } & =(1600+46) 3,1416 \\
& =5171 \mathrm{~mm}
\end{aligned}
$$

Untuk memudahkan proses rolling, ukuran asli bentangan plat akan ditambah sekitar $250 \mathrm{~mm}$ untuk extra bending/kelebihan walls.

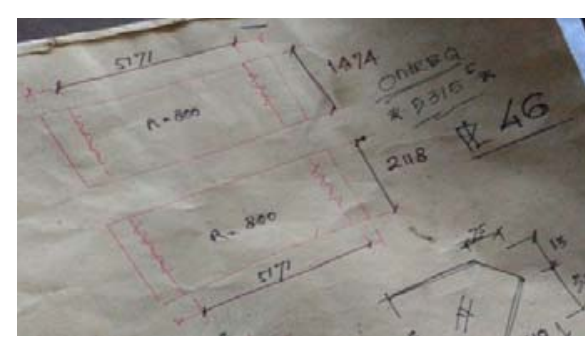

Gbr. 4 Ukuran Bentangan Upper generating Drum

Setelah diketahui panjang bentangan yang dibutuhkan, maka selanjutnya dilakukan proses marking, yaitu penandaan ukuran pada plat. Pada proses marking harus diperhatikan tebal plat yang akan dipotong. Dimana setiap tebal plat memiliki toleransi potong yang berbeda. Oleh karenaya marker harus Menambahkan ukuran standarat toleransi potong dengan ukuran plat yang dibutuhkan.

TABEL I

TOLERANSI POTONG

\begin{tabular}{|c|l|c|}
\hline No & \multicolumn{1}{|c|}{ Tebal Plat } & Toleransi \\
\hline 1. & $3 \mathrm{~mm}-25 \mathrm{~mm}$ & $2 \mathrm{~mm}$ \\
\hline 2. & $30 \mathrm{~mm}-40 \mathrm{~mm}$ & $3 \mathrm{~mm}$ \\
\hline 3. & $50 \mathrm{~mm}-100 \mathrm{~mm}$ & $4 \mathrm{~mm}$ \\
\hline
\end{tabular}

Dilanjutkan proses cuting dengan alat potong brander. Jenis alat potong ini memanfaatkan gas oksigen dan asitilin untuk menghasilkan hembusan api yang stabil sehingga dapat memotong plat baja.

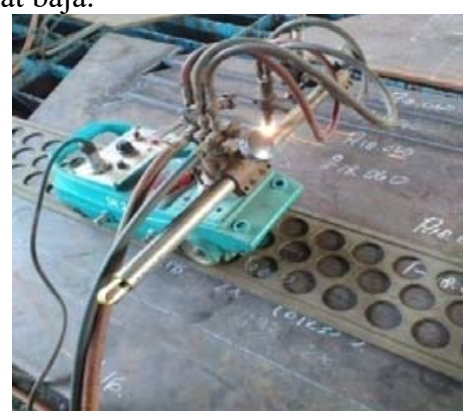

Gbr. 5 Cuting Plat Baja

(Sumber: PT. Bromo Steel Indonesia (BOSTO))

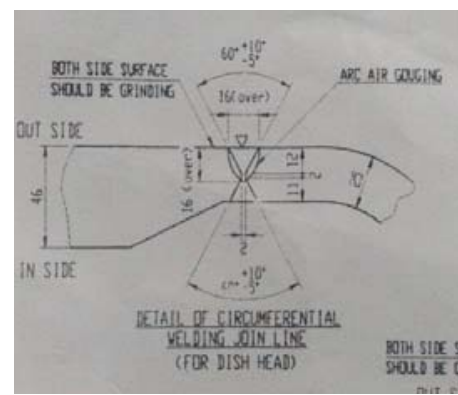

Gbr. 6 Rancangan Ballfront

Dalam penggunaan alat potong brander, untuk menghasilkan hasil pemotongan yang sempurna banyak variabel yang harus diperhatikan. Semakin tebal plat yang dipotong maka kecepatan potong harus diperlambat dan 
semakin besar nozzle yang digunakan. Selain itu, presentase oksigen dan asitilin yang dihembuskan harus seimbang agar menghasilkan hembusan api yang sempurna. Jika terlalu banyak oksigen yang digunakan maka hanya akan menghasilkan hembusan angin dengan api yang tidak bisa memotong plat. Jika terlalu banyak asitilin akan menghasilkan kobaran api tanpa hembusan sehingga tidak bisa memotong plat

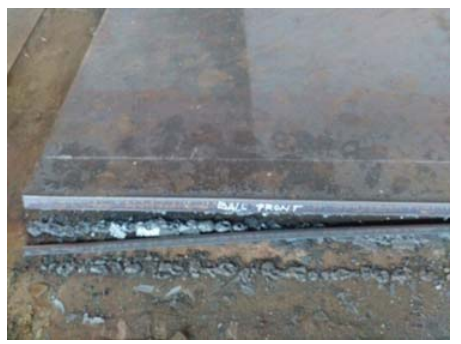

Gbr. 7 Ballfront

(Sumber: PT. Bromo Steel Indonesia (BOSTO))

Sebelum memulai pemotongan baja dikenai perlakuan preheating, yaitu baja dipanaskan hingga berwarna kemerahan. Untuk dapat memotong plat baja nyala api yang digunakan harus netral. Kemudian jalankan mesin brander secara otomatis dengan kecepatan yang sesuai. Pemotongan yang baik akan menghasilkan api tanpa ekor dan juga akan menghasilkan slag yang tidak menumpuk pada hasil pemotongan atau slag tersebut akan jatuh kebawah sehingga tidak menghambat laju pemotongan. Marking cuting juga dilakukan untuk membuat ballfront (penutup Upper Generating Drum) pada tepi plat untuk gambar A1 dan A3.

b. Rolling

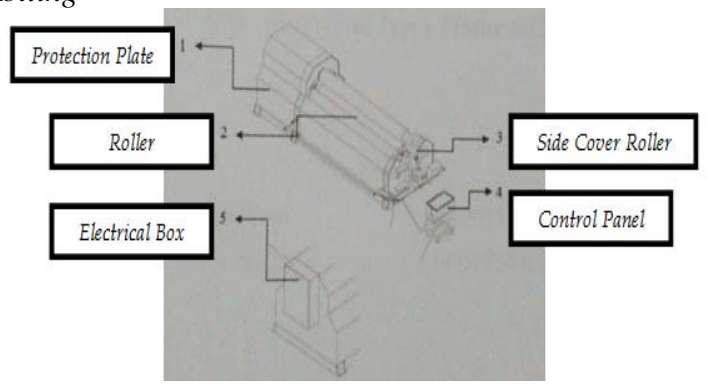

Gbr. 8 Spesifikasi Mesin

Setelah proses marking cuting selesai, plat baja yang sudah terpotong diangkat keatas mesin rolling untuk dilakukan proses rolling. Proses pengangkatan plat baja menggunakan bantuan pesawat angkat craine. Mesin roll yang digunakan adalah AKYAPAK "Hydraulic Four Roller Bending Machine" yang didatangkan dari Turki.

Jenis mesin roll ini menggunakan 4 roller. Roller sayap kiri, roller sayap kanan, dan roller atas dan bawah. Dalam pengoperasiannya, mesin rolling ini memanfaatkan gaya jepit roller atas dan bawah untuk menahan benda kerja. Dan menggunakan roller A dan B untuk merubah bentuk benda kerja.
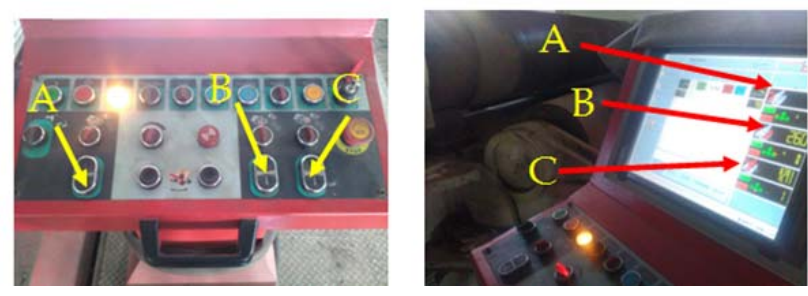

Gbr. 9 Tombol Penggerak Roller

Pengerjaan benda kerja dikendalikan dengan control panel. Dimana di dalam control panel terdapat berbagai tombol perintah. Salah satu perintah utamanya yaitu menggerakkan roller dengan naik, turun, atau berputar. Kode untuk roller sayap kiri adalah $\mathrm{B}$, kode untuk sayap kanan adalah $\mathrm{A}$, dan kode untuk roller atas dan bawah adalah $\mathrm{C}$.

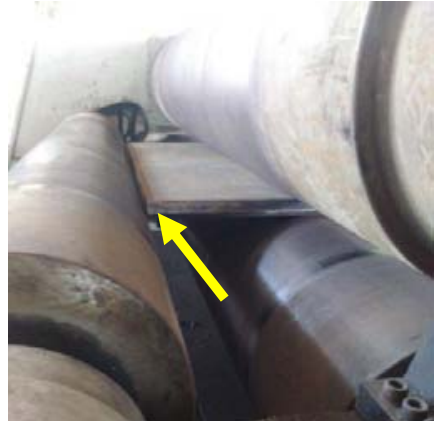

Gbr. 10 Penempatan Center Benda Kerja

Konfigurasi awal proses rolling yaitu menempatkan plat baja pada posisi center pada mesin rolling. Center plat ini nantinya akan mempengaruhi hasil roll, jika plat diroll dalam keadaan tidak center maka akan dihasilkan produk roll yang cacat atau tidak melingkar secara sempurna. Penempatan center cukup mudah, yaitu ujung plat cukup ditempelkan pada roller sayap kanan atau sayap kiri.

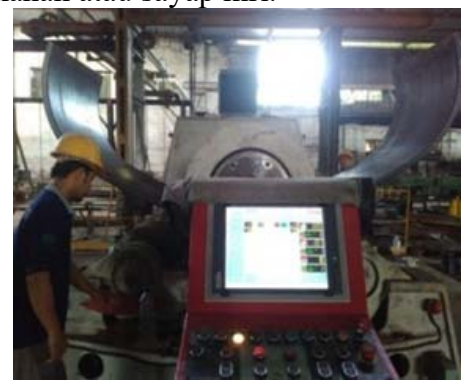

Gbr. 10 Teknik Dasar Pengerolan

Teknik dasar pengerolan yang dilaksanakan yaitu dengan terlebih dahulu membentuk $\mathrm{R}$ (lingkaran) dibagian sisi kiri dan kanan plat sehingga plat akan membentuk huruf $U$ yang panjang. Selanjutnya pengerolan difukuskan pada bagian tengan plat sehingga akan terbentuklah bentuk lingkaran yang sempurna. Teknik seperti ini diyakini akan menghasilkan produk roll yang mendekati R sempurna. Untuk mendapatkan bentuk dasar yang diinginkan seperti gambar diatas maka perlu dilakukan beberapa proses. Pertama, pengerolan difokuskan pada plat bagian kiri. Setelah plat sudah diset dalam keadaan center, operator akan memberi tanda pengerjaan pada sisi kiri plat terlebih untuk memudahkan prosesnya. Penjepitan plat dilakukan pada area extra bending 
yang sudah disiapkan. Area extra bending digunakan untuk menghindari cacat pengerolan akibat proses penjepitan. Untuk mengerjakan bagian sisi kiri plat, maka Plat digerakkan bolakbalik dengan roller $\mathrm{C}$ dari kanan ke kiri pada area bertanda dan level roller sayap kanan dinaikkan per $20 \mathrm{~mm}$ ketika plat baja melewatinya untuk bisa menghasilkan bentuk R.

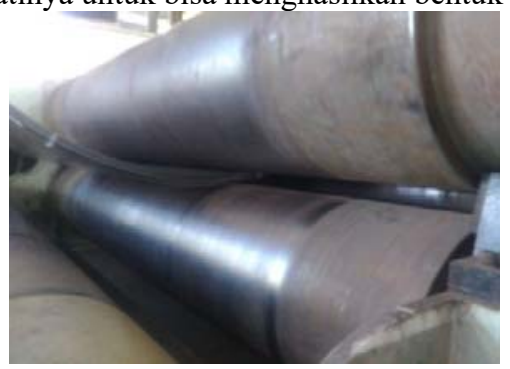

Gbr. 11 Pengerolan Sisi Kiri Plat

Setelah bagian kiri selesai, selanjutnya pengerolan dilanjutkan pada sisi sebelah kanan dengan teknik yang sama hingga plat membentuk huruf $U$ panjang. Selanjutnya, pengerolan difokuskan pada bagian tengah plat untuk menghasilkan bentuk lingkaran. Plat $\mathrm{U}$ digerakkan bolak-balik dari kanan ke kiri dan level roller A dan B akan diturunkan bertahap ketika mendekati bentuk lingkaran untuk mendapatkan nilai diameter yang presisi.

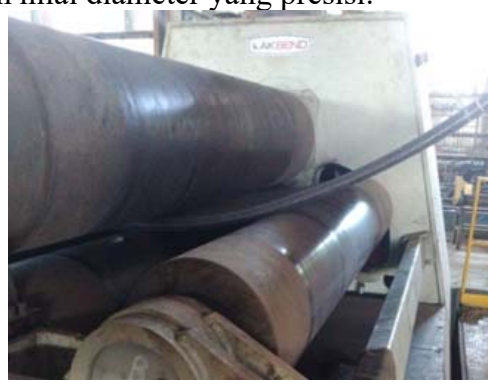

Gbr. 12 Pengerolan Bagian Tengah Plat

Setelah plat membentuk lingkaran yang hampir sempurna, plat roll diturunkan untuk dilakukan pemotongan bagian extra bending.

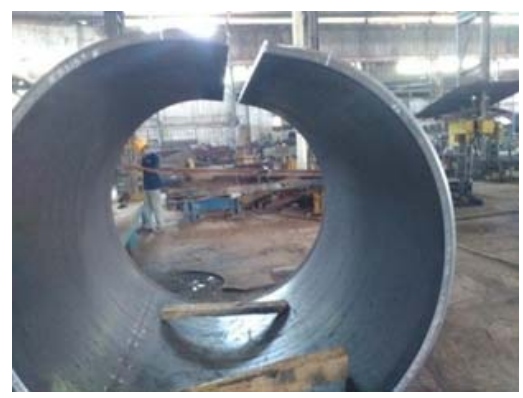

Gbr. 13 Pemotongan Extra Bending

Kemudian plat dinaikan kembali ke mesin roll untuk dipertemukan kedua ujungnya. Proses pemotongan dengan menggunakan brander akan merubah diameter lingkaran. Oleh karena itu, perlu dilakukan pengukuran ulang. Jika diameter lingkaran berubah maka dilakukan proses roll ulang. Jika diameter plat masih dalam ukuran toleransi proses dilanjutkan dengan fitt up, yaitu pemasangan plat sementara sebelum proses pengelasan.

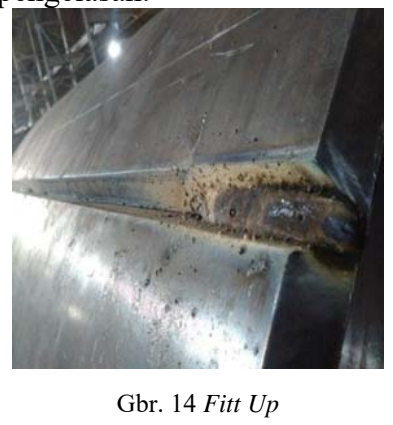

Tahap ini memastikan ukuran diameter produk roll sudah benar, maka tim QC akan melakukan control pada dimensinya. Jika dimensi sudah sesuai dengan gambar maka akan dilanjutkan pada proses pengelasan. Jika dimensi tidak sesuai dengan gambar maka dilakukan pengerolan ulang.

Setelah proses pengelasan, plat akan kembali di roll tahap akhir. Ini dilakukan karena setelah proses pengelasan dimensi plat akan kembali berubah karena panas yang diterimanya.

c. Welding

Proses welding dilakukan dengan 2 tipe pengelasan, SMAW dan $S A W$. pengelasan $S M A W$ dilakukan untuk penyambungan plat dan las $S A W$ untuk pengelasan permukaan hasil pengelasan $S M A W$ agar terlihat lebih bagus dan rapi.

1. Persiapan Las $S M A W$

Pengelasan SMAW menggunakan elektroda $4 \mathrm{~mm}$ dengan tipe LB-52. Untuk teknik pengelasan pada long weld ini, benda kerja agak dimiringkan sedikit ke bagian depan untuk mempercepat proses pengelasan. Selain itu, dengan cara ini hasil pengelasan akan lebih bagus karena elektroda yang mencair akan langsung jatuh di satu titik dan tidak meluber. Sebelum dilakukan proses pengelasan, dibutuhkan alat bantu las berupa tab atau tahu. Tab ini berupa besi tambahan yang direkatkan di kedua ujung benda kerja. Tab akan menjadi titik awal dan akhir pengelasa, jadi ketika selesai pengelasan tab akan dipotong sehingga menghasilkan lasan yang terlihat rapi pada ujung benda kerja.

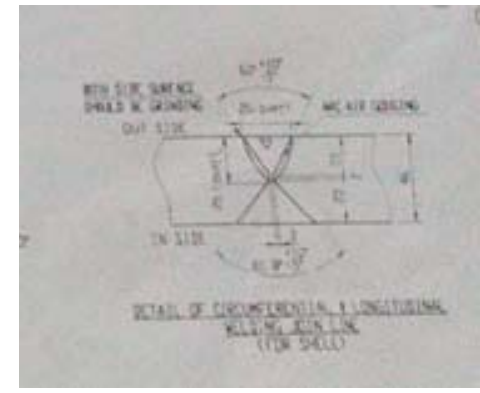

Gbr. 15 Bevel

Pada pengelasan ini bevel yang harus di las tergolong cukup besar, oleh karena itu pengelasan harus dibagi menjadi beberapa layer dan tidak boleh dilakukan dengan satu kali jalan karena akan menghasilkan slag atau void yang akan mempengaruhi kekuatan lasan. Karena ukuran bevel bagian dalam dan luar berbeda maka tentunya jumlah layer akan berbeda sesuai kapasitas isian bevel. 
Setiap welder mempunyai kemampuan dan teknik yang berbeda dalam proses pengelasan ini. Pengelasan dibagi menjadi beberapa jalan sesuai kemampuan ayunan tangan welder.
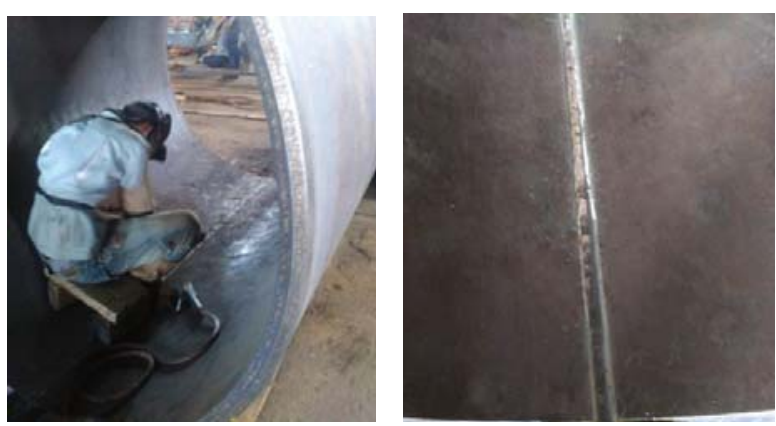

Gbr. 16 Pengelasan SMAW

\section{HASIL DAN DISKUSI}

Setelah pengelasan SMAW selesai dilaksanakan, maka dilakukan kontrol oleh tim QC berupa uji NDT dengan menyemprotkan cairan penetran. Pengujian ini dilakukan untuk memastikan tidak ada cacat pada permukaan hasil lasan.

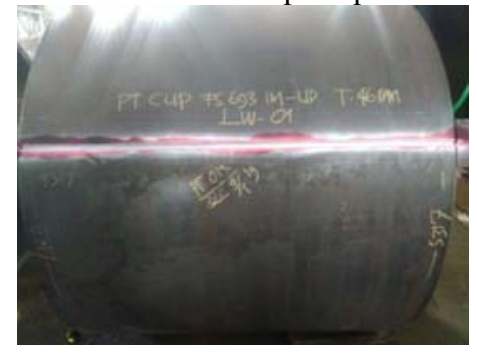

Gbr.17 ACC las SMAW

\section{Las $S A W$}

Setelah hasil pengelasan SMAW lolos QC, selanjutnya dilakukan pengelasan $S A W$ yaitu untuk menutup hasil pengelasan SMAW agar terlihat rapi. Jenis las ini adalah jenis pengelasan yang menggunakan bantuan mesin untuk pelaksanaannya.

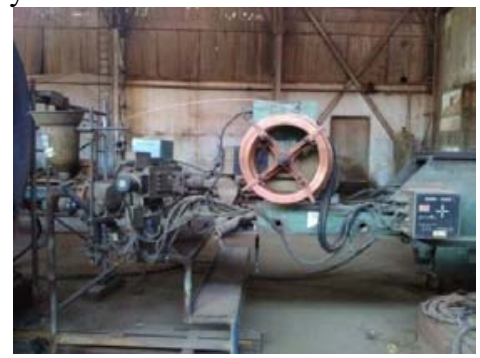

Gbr. 18 Mesin Las SAW

Upaya mencegah oksidasi cairan metal induk digunakan butiran fluks sehingga busur nyala terpendam didalam fluks tersebut.
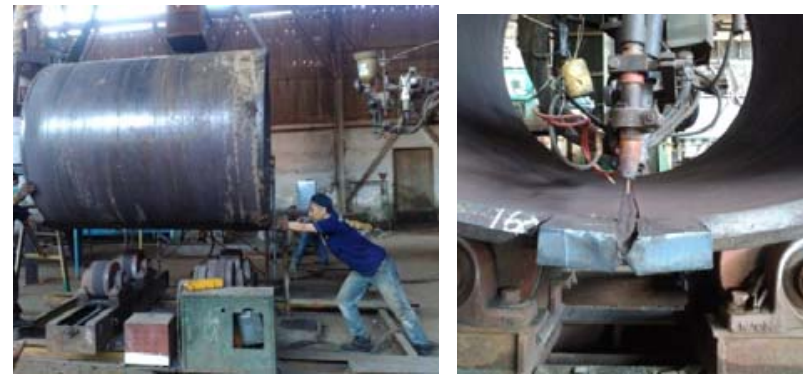

Gbr. 19 Persiapan Benda Kerja

Pertama, benda kerja dinaikkan keatas track dan memposisikan mesin las pada center benda kerja. Benda kerja yang sudah berada pada center dikenai pemanasan untuk menghilangkan kandungan air pada benda kerja untuk mengurangi terjadinya cacat.

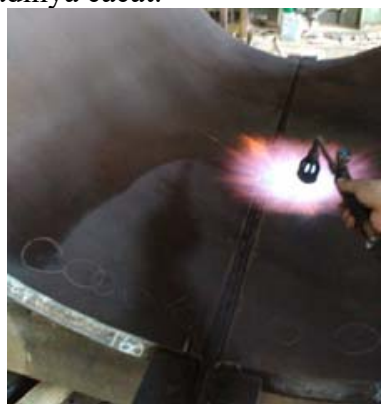

Gbr. 20 Pemanasan Benda Kerja

Selanjutnya persiapan sebelum pengelasan yaitu, pemasangan ground dan mengisi fluks kedalam wadah. Jenis fluks yang digunakan adalah MF-38 produk dari KOBECO. Dalam pengerjaannya, pengelasan dibagi menjadi 3 alur. Sisi kiri, tengah, dan kanan. Pertama dilakukan pengelasan pada sisi kiri kemudian kanan dan terakhir pada bagian tengah.

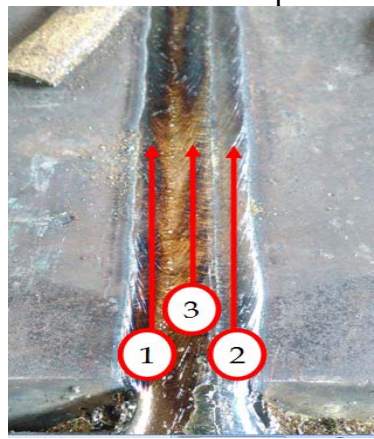

Gbr. 21 Alur Pengelasan SAW

Pada pengelasan di alur 1 dan 2, kecepatan boom pengelasan diatur pada nilai 30 . Kemudian, untuk pengelasan di alur 3 kecepatan boom harus dikurangi agar tidak terjadi cacat undercut. setingan jarak kawat yang digunakan dengan tidak boleh terlalu panjang. Kawat yang terlalu panjang mengakibatkan ledakan selama proses pengelasan sehingga hasil lasan kurang bagus. Setelah persiapan selesai dilakukan, nyalakan mesin dengan menekan tombol dan mesin pun akan berjalan otomatis dengan melakukan proses pengelasan. Selama proses pengelasan fluks akan terus menutupi nyala api. Fluks yang terbakar akan mengeras menjadi kristal. 


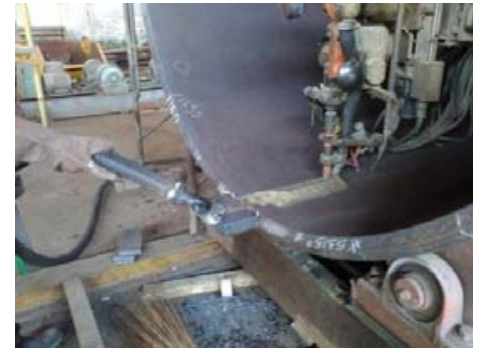

Gbr. 22 Pengelasan SAW

[9] PT BOSTO. 2014. Gambaran Perusahaan, (Online), (http://www. Bromo steelindonesia-ptbosto.com/p/sejarahperusahaanperusahaan-didi rikan.$h t m l)$.

[10] PT BOSTO. 2014. Profil Bromo Steel Indonesia PT, (Online), (http://www.bromosteelindonesia-ptbosto.com/p/profil-bromosteel-indonesia-pt-bosto-pt.html).

Tahap akhir dalam proses ini yaitu, uji hasil lasan dengan uji gama-ray. Dalam proses pengujuian ini dilaksankan oleh pihak ketiga PT. Spektra Megah Semesta. Pengujian ini memanfaatkan tembakan radiasi yang selanjutnya tembakan tersebut akan ditampilan dalam film. Cacat pada bagian dalam pengelasan akan terlihat jelas melalui film tersebut. Dari tiga produk roll semua ACC dan lolos uji gama-ray.

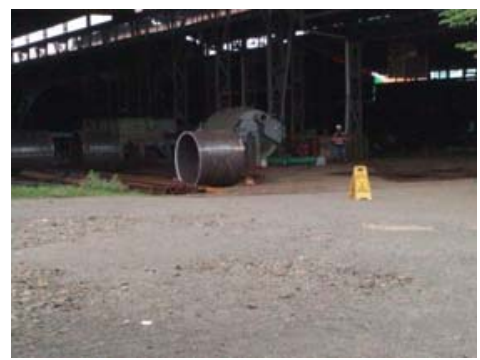

Gbr. 23 Penembakan Radiasi

\section{KESIMPULAN}

Dari semua proses produksi diatas dapat diambil kesimpulan bahwa pembuatan komponen body upper generating drum melewati beberapa tahapan yaitu: persiapan material, persiapan marking cutting, proses marking cutting, proses rolling, proses welding, dan terakhir yaitu proses control product (QC) untuk menjamin kualitas pengerjaan.

\section{REFERENSI}

[1] Aprilian, Dicky. 2018. Proses Rolling Reflux Drum (Super Grade). Jember: PPs Universitas Jember

[2] Djarwanto. 1982. Pengertian Rolling, (Online), (http://teknikmesinmanu faktur.blogspot.co.id/2015/06/rolling.html).

[3] Duskiardi. 1982. Makalah Pengerolan Logam, (Online), (http:// www.acade mia.edu/23849510/Makalah_Rolling.html).

[4] Suyono, Joko. 2016. Proses dan Jenis Pengelasan. Pasuruan: PT. Bromo Steel Indonesia.

[5] Teknologi, Artikel. Prinsip Kerja Superheater, (Online), (http://artikel-teknologi.com/prinsip-kerja-superheater/)

[6] Teknologi, Artikel. Steam Drum Pada Boiler Pipa Air, (Online), (http:// artikel-teknologi.com/steam-drum-pada-boiler-pipa-air/)

[7] Tim Penyusun. (2014). "Buku Panduan Praktik Industri (PI)/Praktik Kerja Lapangan (PKL) Fakultas Teknik Unesa". Surabaya: Unesa Press

[8] PT BOSTO. 2014. Denah Perusahaan, (Online), (http://www. Bromosteel indonesia-ptbosto.com/p/blog page 5261.html). 